\title{
MIXED APPROACH FOR SCHEDULING PROCESS IN WIMAX FOR HIGH QOS
}

\author{
Surinder Singh ${ }^{1}$, Simarpreet Kaur $^{2}$ \\ ${ }^{1}$ Student, Baba Banda Singh Bahadur Engineering College, Department of Electronics \& Communication \\ Engineering, Fatehgarh Sahib 140-406, Punjab, India \\ ${ }^{2}$ Baba Banda Singh Bahadur Engineering College, Department of Electronics \& Communication \\ Engineering,Fatehgarh Sahib 140-406, Punjab, India
}

\begin{abstract}
WiMAX(worldwide interoperability for Microwave Access) networks are the networks which are responsible for providing many services like video, data and voice. The WiMAX technology satisfies the modern need of broadband internet through wireless access. For managing all these services through WiMAX, IEEE802.16 gives QOS (Quality of Service) parameter. In WiMAX, a fundamental challenge is to achieve high QOS so that various parameters like waiting time, end to end delay can be minimized and other parameter like execution time and network utilization etc. To obtain high QOS there is scheduling algorithm which is implemented at the base station and subscriber stations. In this paper we discuss scheduling algorithms and also compare the parameters (waiting time, turnaround time, execution time, packet drop age and packet delivery). We purpose a scheduling algorithm which is combination of greedy latency, distance calculation of user from base station, calculate the burst time and apply SJF on that burst values.
\end{abstract}

Keywords: WiMAX, QOS, IEEE802.16, Scheduling, FCFS (first come first serve), SJF(Shortest job First), Latency.

$* * *$

\section{INTRODUCTION}

WiMAX is a telecommunication protocol which provides internet access. The internet access May be fixed and mobile internet. It provides the longer data communication.. It offers high speed connection to internet. There are many services that are provided through this protocol that is voice, data, video and web browsing. In other words we can say it is a BWA (broadband wireless access). The BWA helps to use internet with broadband speed but through wireless access.

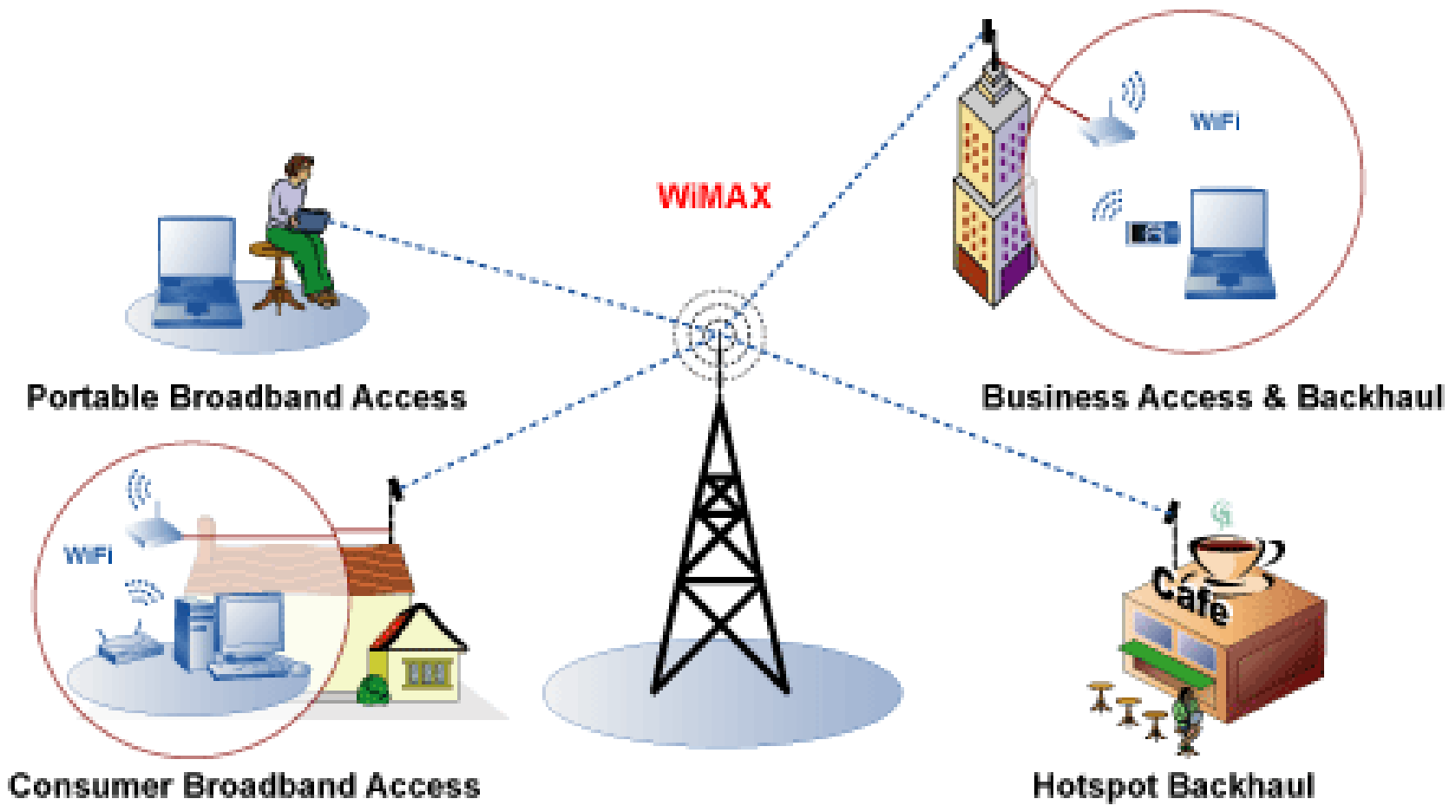

Fig: 1.1 WiMAX(WiMAX(worldwide interoperability for Microwave Access) 


\section{WIMAX ARCHITECTURE}

The IEEE 802.16 gives a standard to the WiMAX. According to this standard the WiMAX consist of one BS (base station) and one or more SSs (Subscriber stations). The base station as the name indicates that it is the base of any data transmission through WiMAX. Without base station it is not possible to provide any service through WiMAX. The other language of Base station is the backbone of the WiMAX. As far as the construction layout of the base station, it is similar to the cell phone tower. The range of the base station is the radius of 6 miles. In WiMAX the communication link between Base station and Subscriber station is through the microwave dishes. The subscriber station consists of one or more users.

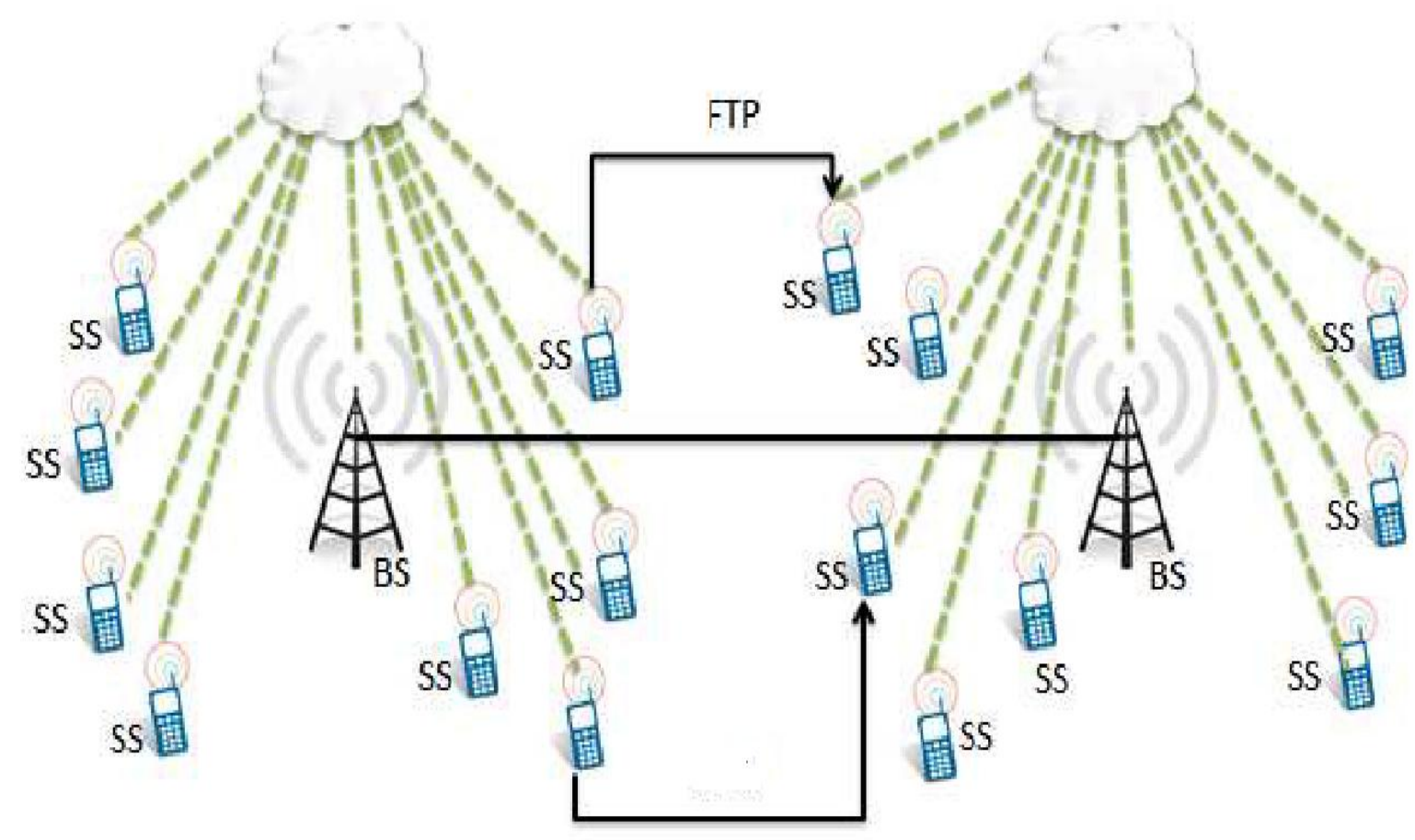

Fig: 2.1 WiMAX Architecture

\section{QUALITY OF SERVICE (QOS)}

The QoS as the name indicates that a quality of WiMAX. Or in other words we can say that how effectively WiMAX can manage the network with minimum delay and waiting time. The ideal aim of the WiMAX is to provide available recourses among all the users. To meet all above requirement the IEEE802.16 gives a standard which categorized the traffic in five classes. This basic standard will help to categories the traffic. These categories of traffic are called classes. These classes are called UGS (Unsolicited Grant Service),rtPS(real-time Polling Service),nrtPS(non real-time Polling Service),ertPS(Extended Real-time Polling Service) and BE(Best Effort). Reka R.[44] The table 3.1 shows the QoS classes, specification and application.

Table 3.1 QoS Applications and Specifications

\begin{tabular}{|l|l|l|}
\hline Quality of Service Class & Application & QoS Specification \\
\hline $\begin{array}{l}\text { Unsolicited Grant Service } \\
\text { (UGS) }\end{array}$ & Voice over IP (VoIP) & $\begin{array}{l}\text { Maximum substained rate, Maximum latency } \\
\text { tolerance, Jitter tolerance }\end{array}$ \\
\hline $\begin{array}{l}\text { Real-time Polling Services } \\
\text { (rtPS) }\end{array}$ & MPEG video & $\begin{array}{l}\text { Minimum reserved rate, Maximum } \\
\text { substained rate, Maximum latency tolerance, } \\
\text { Traffic priority }\end{array}$ \\
\hline $\begin{array}{l}\text { Non Real-time Polling } \\
\text { Services (nrtPS) }\end{array}$ & $\begin{array}{l}\text { File Transfer Protocol } \\
\text { (FTP) }\end{array}$ & $\begin{array}{l}\text { Minimum reserved rate, Maximum } \\
\text { substained rate, Traffic priority }\end{array}$ \\
\hline Best Effort (BE) & $\begin{array}{l}\text { Web browsing, data } \\
\text { transfer }\end{array}$ & Maximum substained rate, Traffic priority \\
\hline $\begin{array}{l}\text { Extended Real-time Polling } \\
\text { Service (ertPS) }\end{array}$ & $\begin{array}{l}\text { Voice with activity } \\
\text { detection (VOIP) }\end{array}$ & $\begin{array}{l}\text { Minimum reserved rate, Maximum } \\
\text { substained rate, Maximum latency tolerance } \\
\text { Jitter tolerance Traffic priority }\end{array}$ \\
\hline
\end{tabular}




\section{SCHEDULER}

As we discussed earlier in WiMAX there is base station and subscriber station. A subscriber station and a base station will handle the traffic of incoming packets. The traffic of packets may be of different-different priority. These incoming packets are passing through the classifier. The classifier will classify the packets according to IEEE802.16 standard. As discussed earlier there are five classes in which the incoming traffic will be classified. Each class is responsible for different application. Once the packets are classified according the IEEE802.16 standards, after that these packets are placed into multi-priority queue. In this queue these packets are placed from high priority to low priority. In this queue basically four queues are present. These queues are high priority queue, medium priority queue, normal priority queue and low priority queue. After that the application of scheduler comes into the picture.

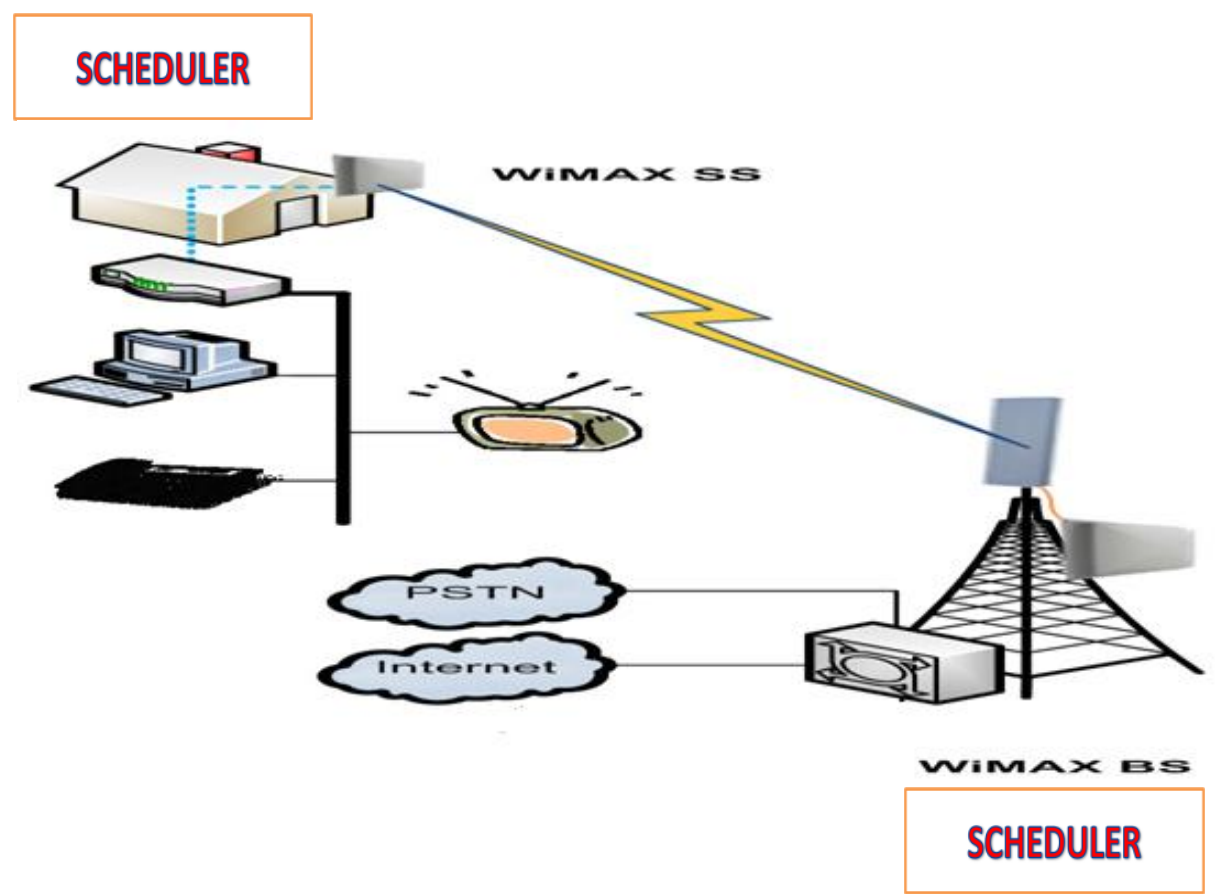

Fig 4.1 Scheduler in BS and SS

A Scheduler executes the process according to priority of processes. A scheduler is present in base station as well as in the subscriber station. Fig 4.1 shows the diagram of WiMAX in which application of scheduler clearly shown. As shown in the diagram a scheduler is present in the base station and also present in the subscriber station.

A scheduler executes all incoming process according the priority set by the multi-priority queue. It also shows the how base station is connected through microwave link to the subscriber station.

\section{FUNCTIONAL BLOCK DIAGRAM FOR SCHEDULER.}

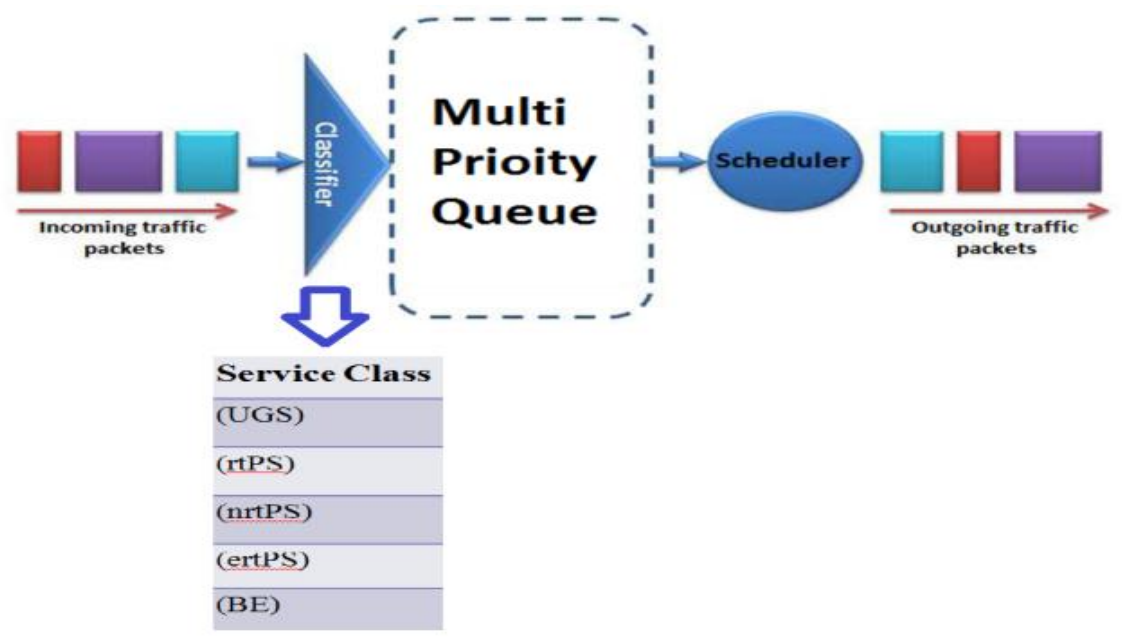

Fig 5.1 functional block diagram of scheduler 
Fig 5.1 shows the functional block diagram of scheduler in which it shows that all incoming packets are given to the classifier. After that it is given to the multi-priority queue. After that it is given to the scheduler. Al-Howaide [6] the scheduler executes all incoming packets according to the priority set by the multi-priority queue.

\section{ALGORITHMS USED FOR SCHEDULING}

Scheduling algorithms supports two type of execution. In first type they can support execution of process without any interruption and in second type of process any process which is under execution can be interrupted. According to that there are two categories of scheduling Algorithms. These are as follows.

A. Non Preemptive scheduling algorithms: In Non Preemptive Scheduling algorithms if the task is going to be executed, in between the execution if any other task with higher priority is present in the ready queue then there is no effect on the processing task. e.g FCFS,SJF,SP.

B. Preemptive scheduling algorithms: In Preemptive Scheduling algorithms if the task is going to be executed, in between the execution if any other task with higher priority is present in the ready queue then current task with higher priority will execute first. e.g RR,WRR.

\subsection{FCFS (First Come First Serve) Scheduling Algorithm}

As the name indicates that in that type of scheduling the first job will execute first and after that second job will execute and after that third job will execute and so on. The jobs which are entering into the ready queue first will execute first. As shown in the following fig no 6.1 that in FCFS algorithm there is waiting queue and ready queue. The process assigned with priorities are entering into the waiting queue and then first come first serve basis they are entered into the ready queue.

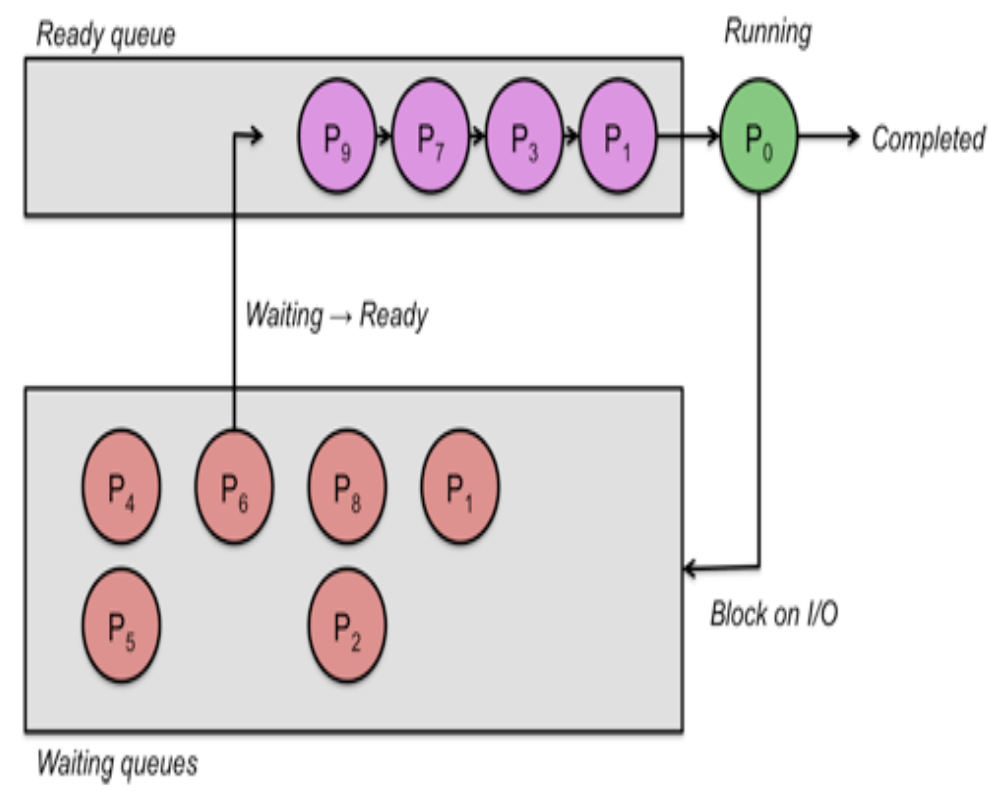

Fig 6.1 FCFS

\subsection{SJF (Shortest Job First) Algorithm}

In that type of scheduling algorithm the job with less burst time will be executed first. The jobs are present in the ready queue, the job with less burst time will execute first and so on.

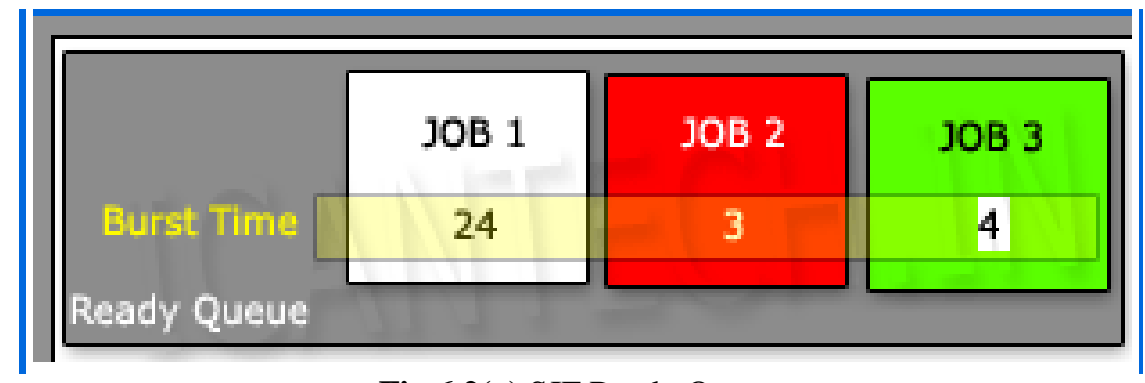

Fig 6.2(a) SJF Ready Queue 


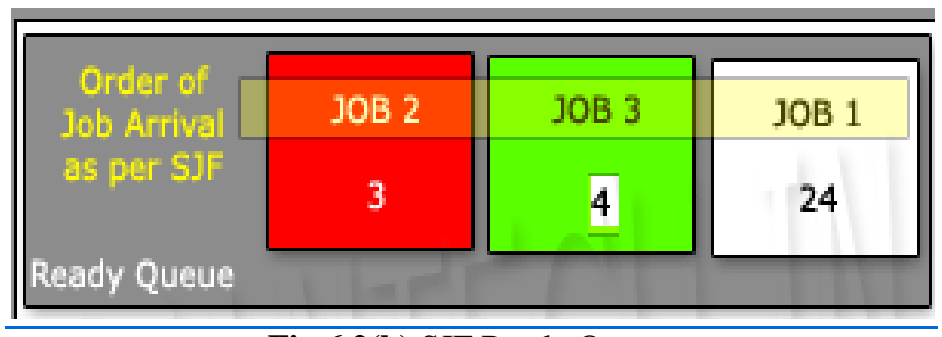

Fig 6.2(b) SJF Ready Queue

As shown in the above figure 6.2(a) the ready queue before applying the SJF algorithm and figure 6.2(b) shows the SJF ready queue after applying a SJF algorithm.

\subsection{Strict Priority Scheduling or Priority Scheduling}

As the name indicates that in that type of scheduling the execution of jobs are done on the basis of priority assigned to the jobs. The jobs assigned with highest priority will execute first and jobs with low priority will execute after higher priority job. This is also non-preemptive type scheduling that is as soon as the higher priority jobs are executed the lower jobs cannot execute. As shown in the following diagram the incoming packets are passing through the classifier. A classifier classifies or divided the packets according to the IEEE 802.11 standard. After the classifier the packets are placed into the multi-level queue. In that queue the jobs with higher priority are placed into higher priority queue. Similarly the job with medium priority jobs is placed into the medium priority queue. The job with lower priority is placed into the lower priority queue as shown in following Fig 6.3 .

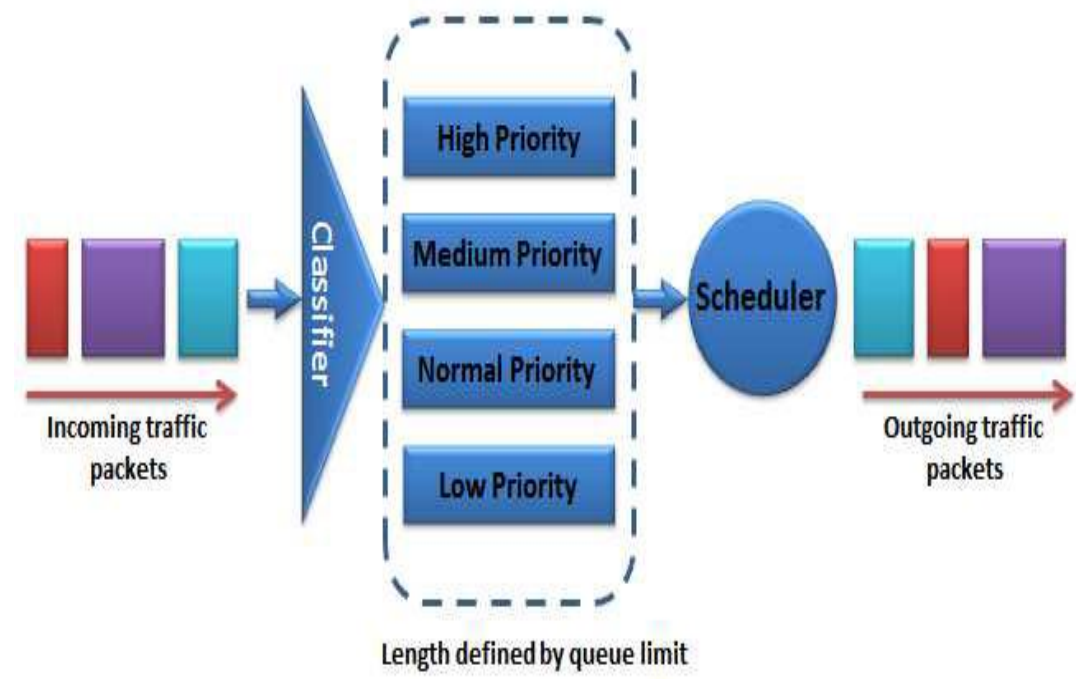

Fig.6.3 Strict priority Scheduling

\subsection{Greedy -Latency Scheduling}

In greedy latency scheduling algorithm the three parameters are considered for efficient scheduling. Firstly these three parameters are calculated then the scheduler starts serving all these packets. These three parameters are packet latency, Packet dropping and channel condition.

Packet Latency: The latency is basically a delay in the transmission, so packet latency is referred to as the delay between the transmissions of packet from source to destination.

Channel condition: The channel condition can also be taken into account while scheduling. The greedy latency scheduler can take this parameter also for scheduling.

Packet dropping: The packet arrival is must to reach at the base station but due to channel condition and delay; sometime the packets are showing more and more latency. During this condition these packets having maximum latency can be dropped. The process of packet drooping can also be calculated in this scheduling algorithm. The formula for calculating the utility value is Assume packets waiting in the queu $=\mathrm{N}$

Maximum admissible Latency $=\mathrm{Tk}$. 
The utility function for kth user is given by: $\quad \mathrm{U}(\mathrm{d}, \mathrm{t}, \gamma)=$

$$
\begin{aligned}
& \left\{\arg \operatorname{maxk}\left(\mathrm{dk} / \mathrm{Tk} \gamma^{-} k\right) \text { for } \mathrm{dk} / \mathrm{Tk}<1\right. \\
& \text { Packet drop for } \mathrm{dk} / \mathrm{Tk}>1
\end{aligned}
$$

$\mathrm{Tk}>0, \mathrm{dk}>0 \quad \forall \mathrm{k} \in\{1,2,3, \ldots, \mathrm{N}\}$

$\mathrm{dk}=$ packet scheduled time - packet arrival time

$$
\begin{aligned}
& \gamma \bar{k}=\text { avearge } S N R \\
& \mathrm{dk}=\text { packet latency }
\end{aligned}
$$

Firstly $\mathrm{dk}$ is calculated after that $\alpha$ is calculated, if $\alpha<1$ then utility function is calculated otherwise packet dropped. After that sort the utility function values in descending order. Figure 6.4 shows the greedy Latency scheduling.

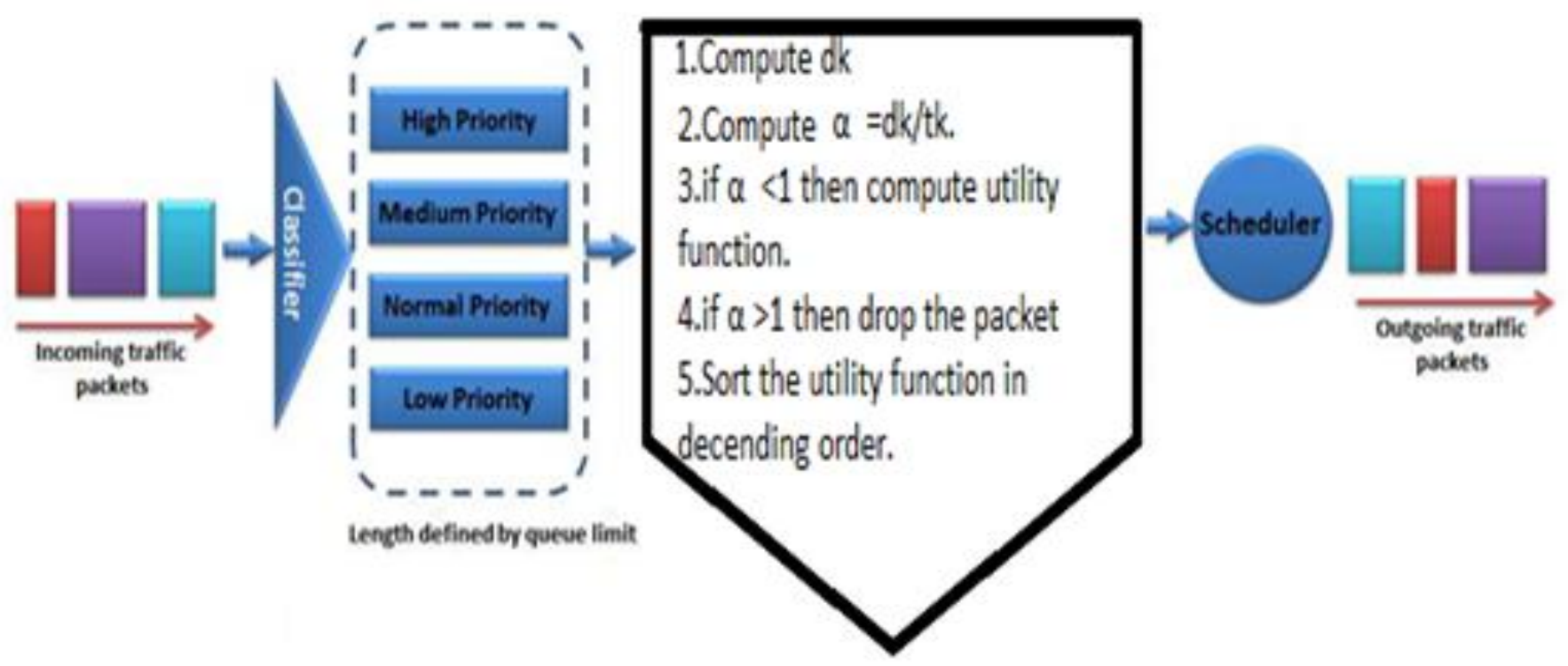

Fig 6.4 greedy Latency scheduling

\section{PROPOSED WORK}

Proposed method shows the scheduling algorithm parameters. The parameters are execution time, Average waiting time, Average turnaround time, Packet delivery and packet drop age. The simulation result shows that the execution of process on each node can be faster than previous approach. The average turnaround time can also reduce, the average turnaround time can also be reduced, the packet delivery can be incensed and packet drop age will be less. Figure 7.1 Shows the flow chart for propose model.

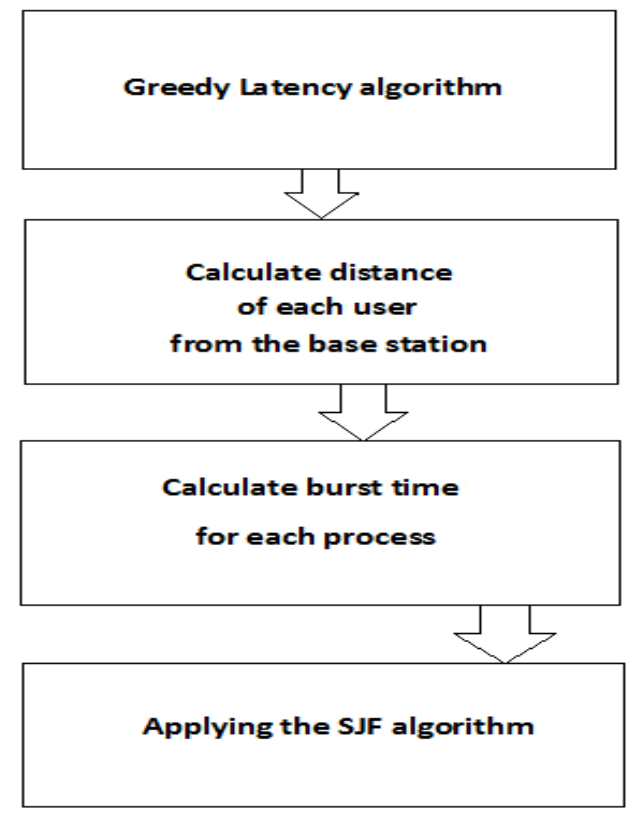

Fig 7.2 Proposed Scheduling Algorithm 
In our purposed model the user can be scheduled according to greedy latency scheduler. The further concept which we can add in our approach is that after applying the greedy Latency scheduling, the distance of each user from the base station can be calculated. As which node has shorter distance from the base station, take less time to execute, as distance is directly proportional to the time. As the distance is less the time taken by the packet to reach at the base station is less hence burst time for each process can be reduced. After that the process having less burst value can be executed first. This is done by applying the SJF algorithm. The result shows by applying this approach the execution time, Average waiting time, Average turnaround time, Packet delivery and packet drop age parameters can be changed.

\section{SIMULATION RESULTS}

For performing the experiments we consider number of parameters. Following is the table for simulation parameters.

Table 8.1 Simulation Parameters values

\begin{tabular}{|l|l|}
\hline Parameter & Value \\
\hline Size of Network & $50 \mathrm{~m}$ x 50m \\
\hline Number of users & 7 \\
\hline Base station Position & $\mathrm{X}=25, \mathrm{Y}=45$ \\
\hline Nodes position & Random \\
\hline Name of users & $\begin{array}{l}\text { Users=1, Users=2, Users=3, Users=4, } \\
\text { Users=5, Users=6, Users=7 }\end{array}$ \\
\hline Type of Process & 4 \\
\hline $\begin{array}{l}\text { Brust time for each } \\
\text { Process }\end{array}$ & {$[51,220,770,684] \mathrm{ms}$} \\
\hline $\begin{array}{l}\text { Maximum Brust time } \\
\text { for each process }\end{array}$ & {$[160,400,1000,1000] \mathrm{ms}$} \\
\hline $\begin{array}{l}\text { Name of Process } \\
\text { Packet Scheding } \\
\text { times }\end{array}$ & Web browsing, Gaming \\
\hline Packet Arrival times & {$[13,57,42,2,34,22,84] \mathrm{ms}$} \\
\hline $\begin{array}{l}\text { Allocation of process } \\
\text { for each user for } \\
\text { simulation }\end{array}$ & {$[1,2,3,4,1,2,3]$} \\
\hline
\end{tabular}

Figure 8.1 shows the network area with base station and users. The location of base station is $\mathrm{x}=25, \mathrm{y}=45$. The location of users are random. Figure 7.2 shows the graph of process number v/s burst time.

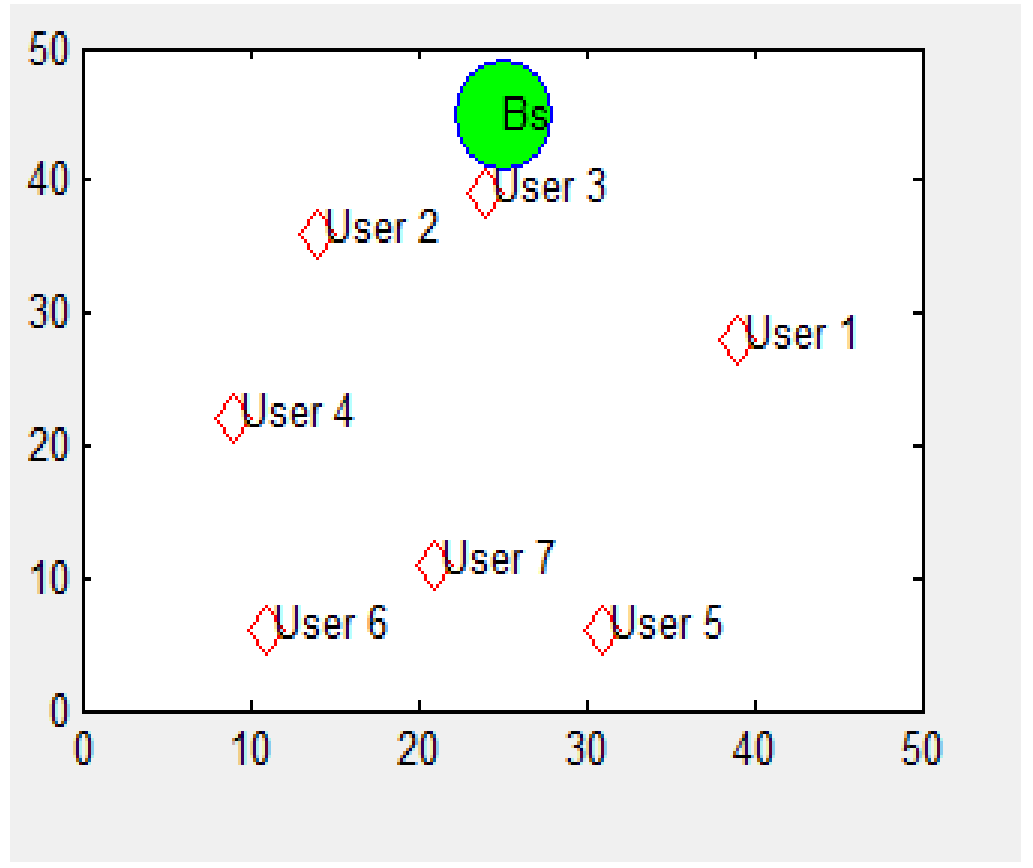

Fig: 8.1 Area of the network with Base station and the users 


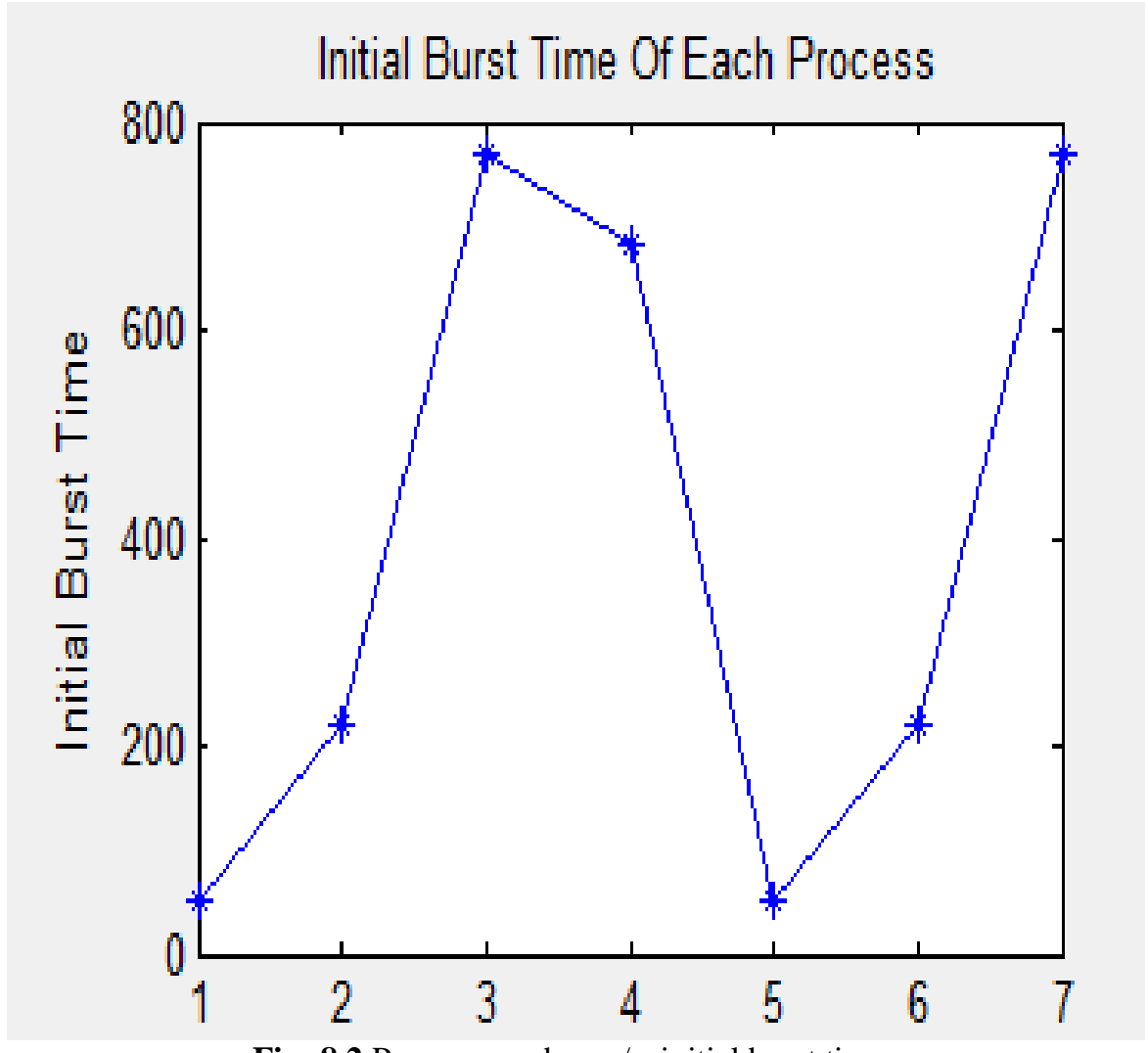

Fig: 8.2 Process number v/s initial burst time.

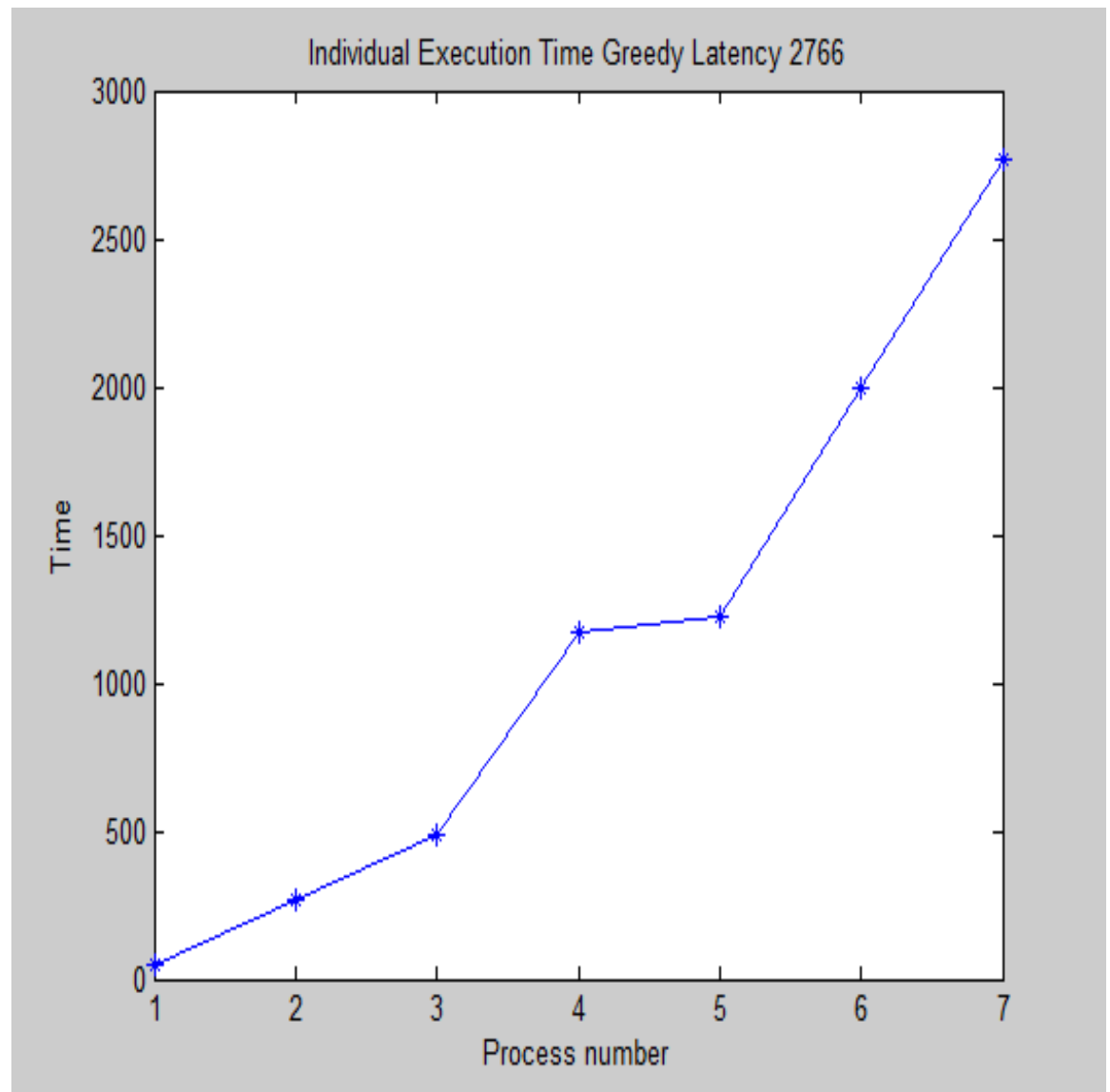

Fig: 8.3 Individual execution time greedy Latency. 


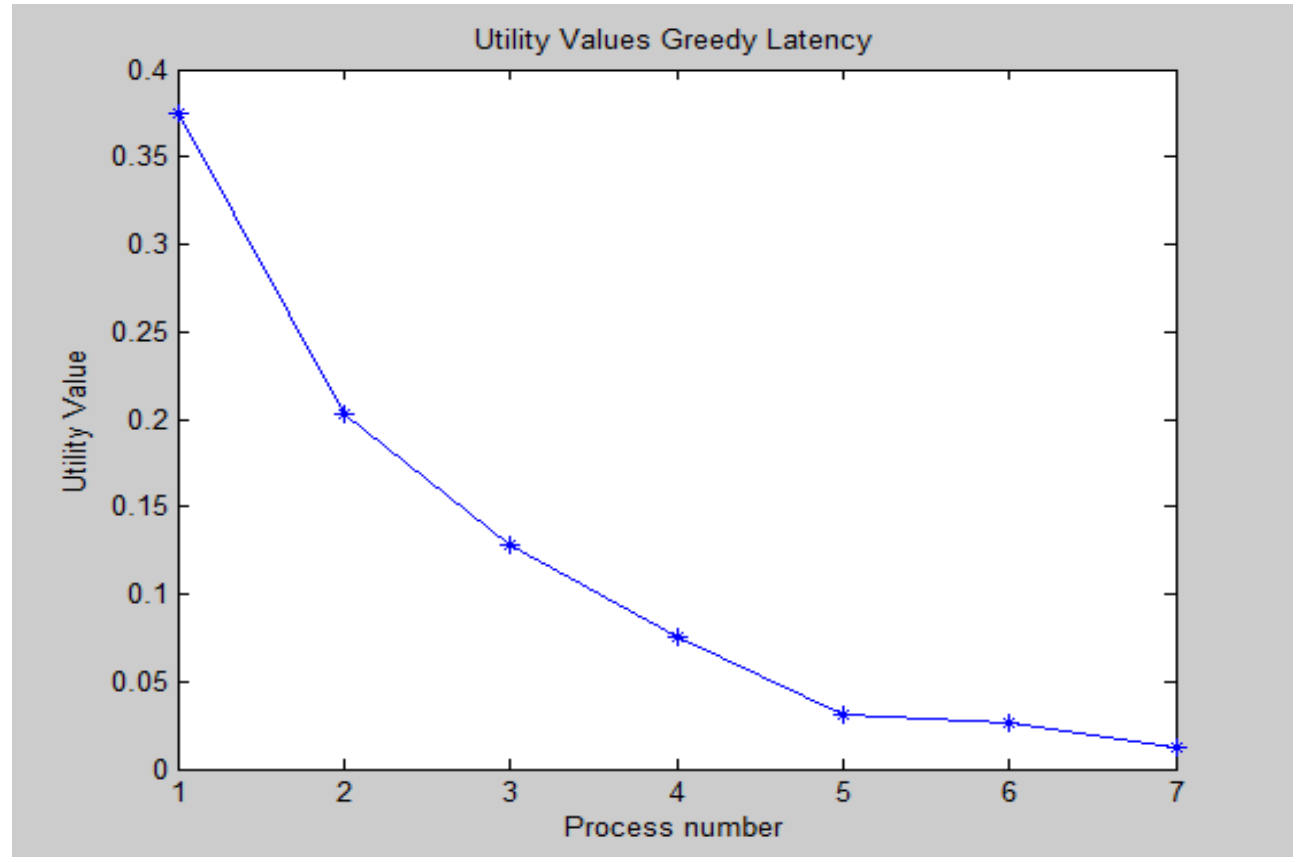

Fig: 8.4 Process number v/s utility value with greedy Latency.

Figure 8.3 shows the execution time for each process for each user with greedy latency Scheduler. The execution time for each user shown by $\left(^{*}\right)$ on the graph. The graph also gives the total execution time for all process. The burst value for each user is the given values in the program. The values of burst time for each process are shown in the parameter table.

Figure 8.4 shows the utility values for each process of each user with greedy latency scheduler. The utility value for each user shown by $(*)$ on the graph. The utility value can be calculated with utility function of greedy latency scheduler. The utility values are the ratio of max value of $\mathrm{dk} / \mathrm{tk}$.

Figure 8.5 shows the execution time for each process for each user with proposed Scheduler. The execution time for each user shown by $(*)$ on the graph. The graph also gives the total execution time for all process. The burst value for now changed in the proposed scheduling. The values of burst time for each process are now calculated by first calculating the distance from base station of each user. The user which is closer to base station have less burst time.

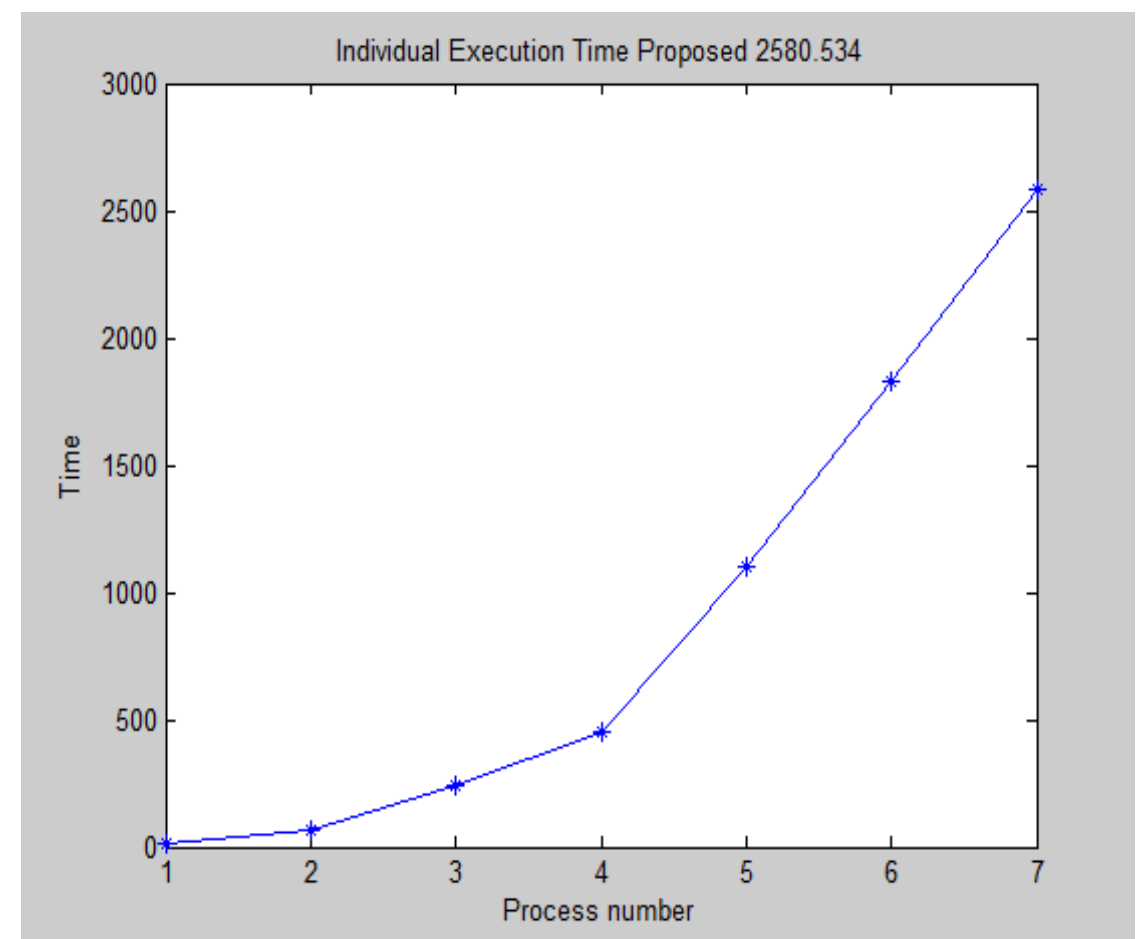

Fig: 8.5 Individual Execution Time proposed (Process number vs time) 


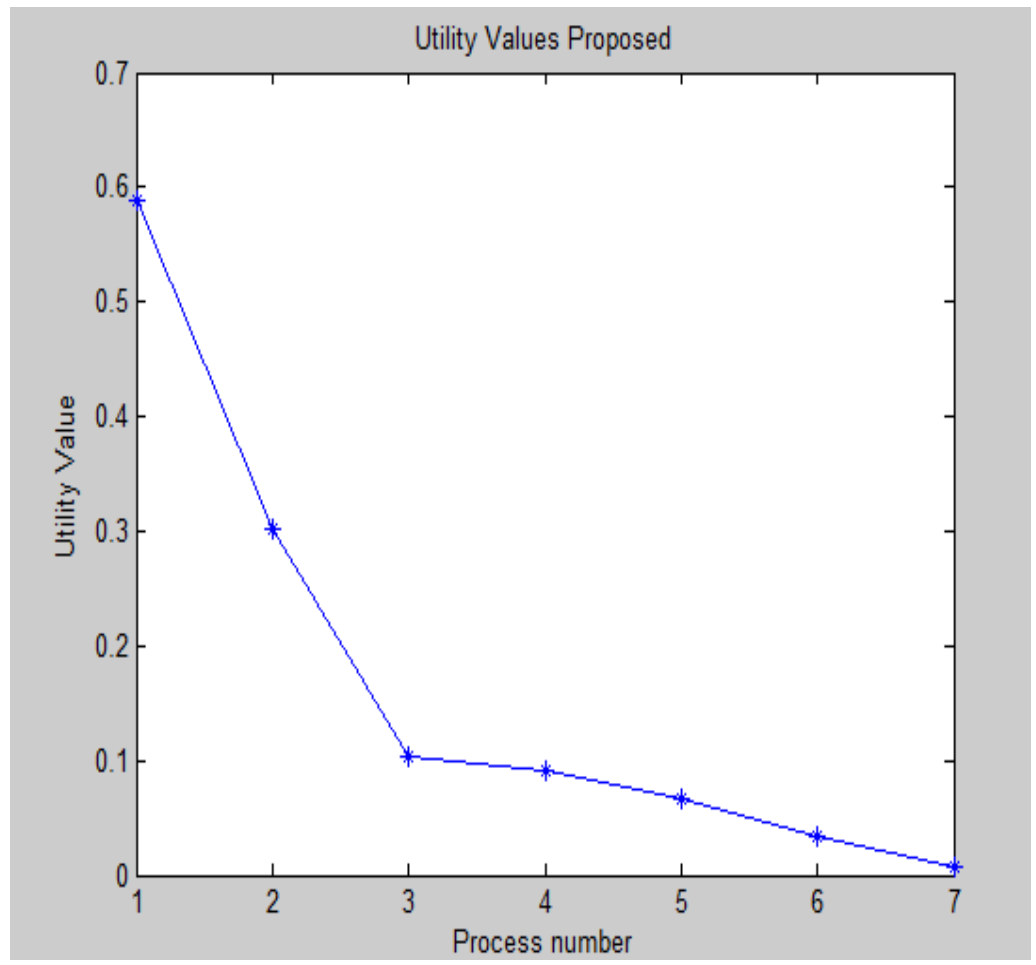

Fig: 8.6 Process number v/s utility value (proposed).

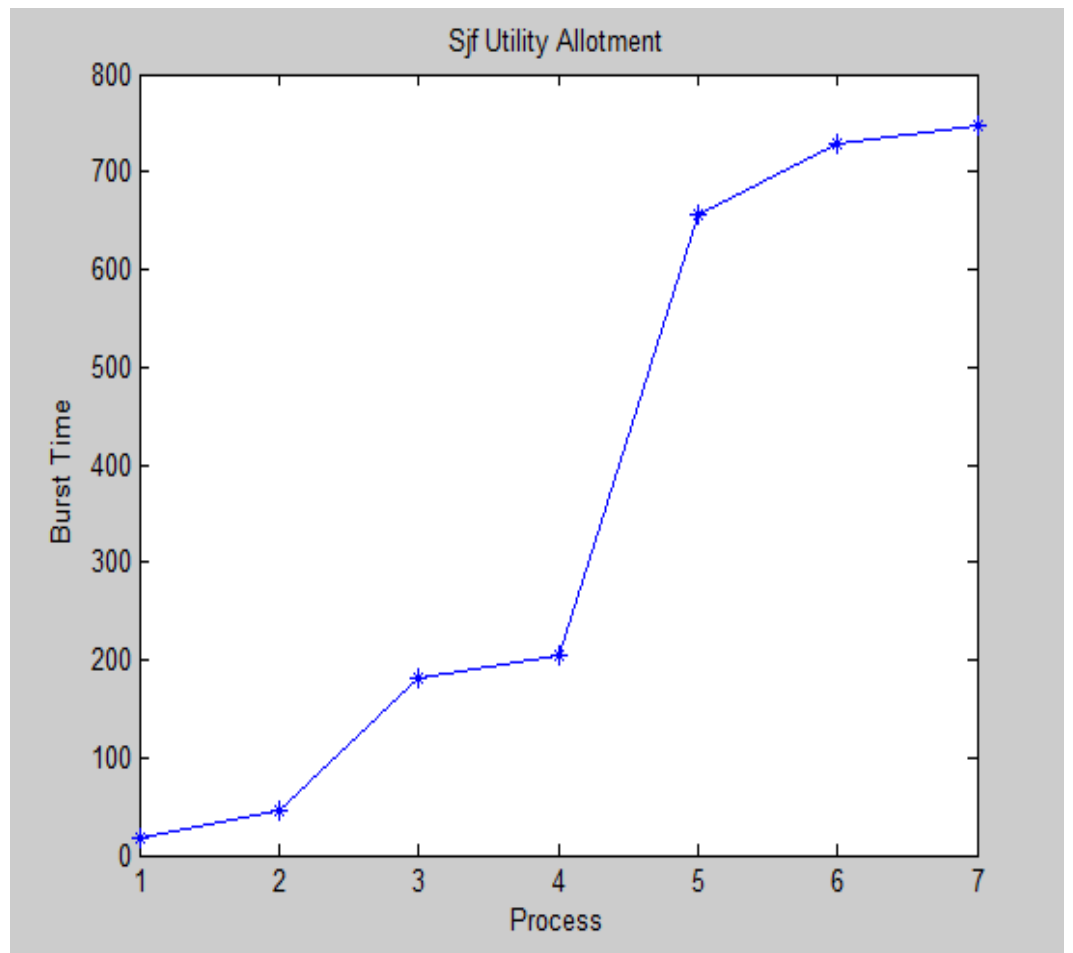

Fig: 8.7 Burst time v/s Process (SJF Utility allotment)

Figure 8.6 shows the utility values for each process of each user with proposed scheduler. The utility value for each user shown by $(*)$ on the graph. The utility value can be calculated with utility function of greedy latency scheduler. The utility values are the ratio of max value of $\mathrm{dk} / \mathrm{tk}$.

Figure 8.7 shows the SJF (shortest job first) of burst values for proposed algorithm. The allotment of job for each user shown by $\left.{ }^{*}\right)$ on the graph. The burst values are calculated by the proposed algorithm. In SJF algorithm the user having less burst time can execute first and so on. It will have the great impact on the total execution time. 
Figure 8.8 shows the comparison of packet delivery/drop age of greedy latency scheduling and proposed algorithm. The comparison of packet delivery/drop age of greedy latency with proposed algorithm scheduling for each user shown by $(*)$ with blue line on the graph. The comparison of packet delivery/drop age of proposed scheduling with greedy latency for each user shown by $(*)$ with red line on the graph. The packet delivery is more in proposed scheduling

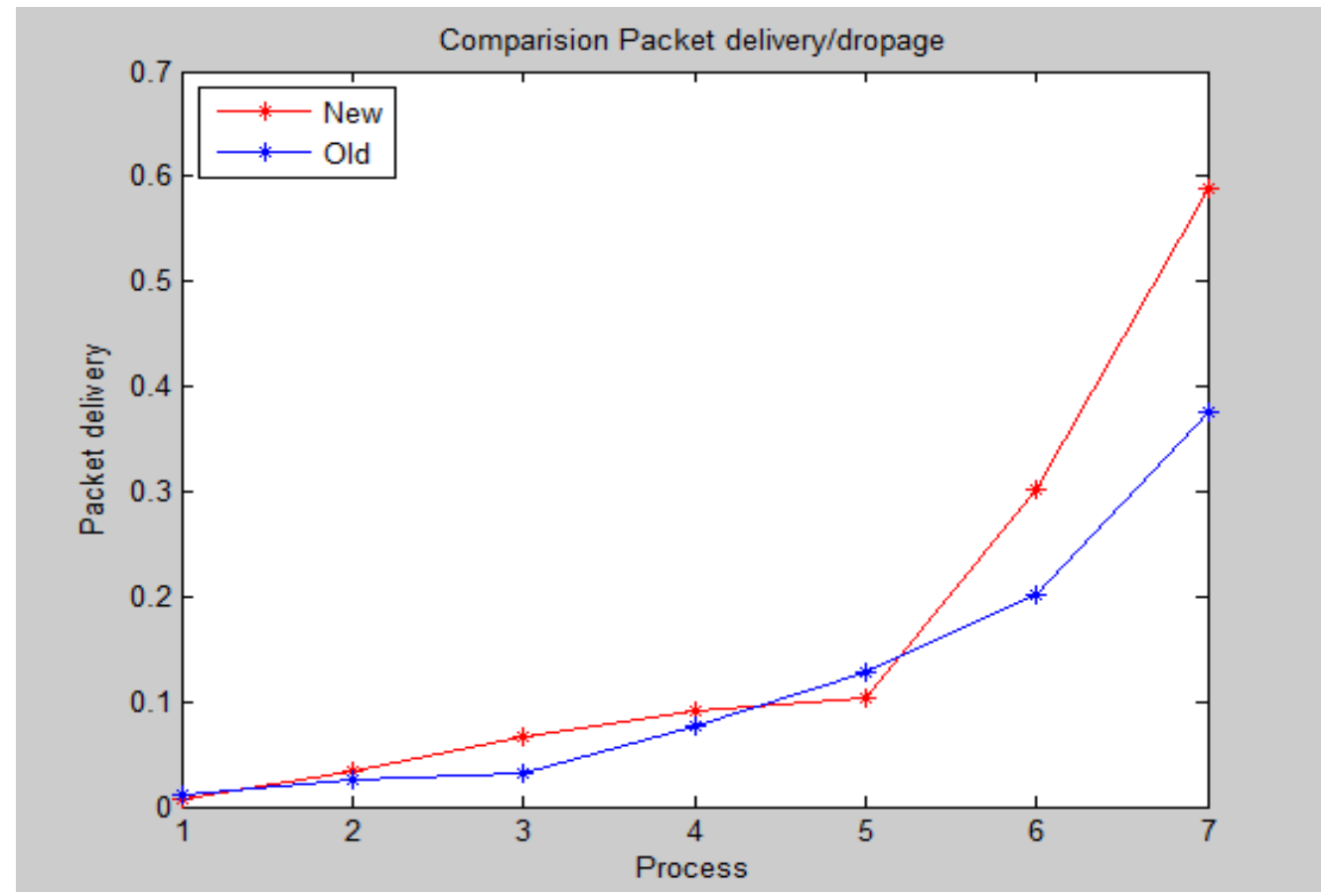

Fig: 8.8 Packet delivery v/s process (Comparison packet delivery/dropage)

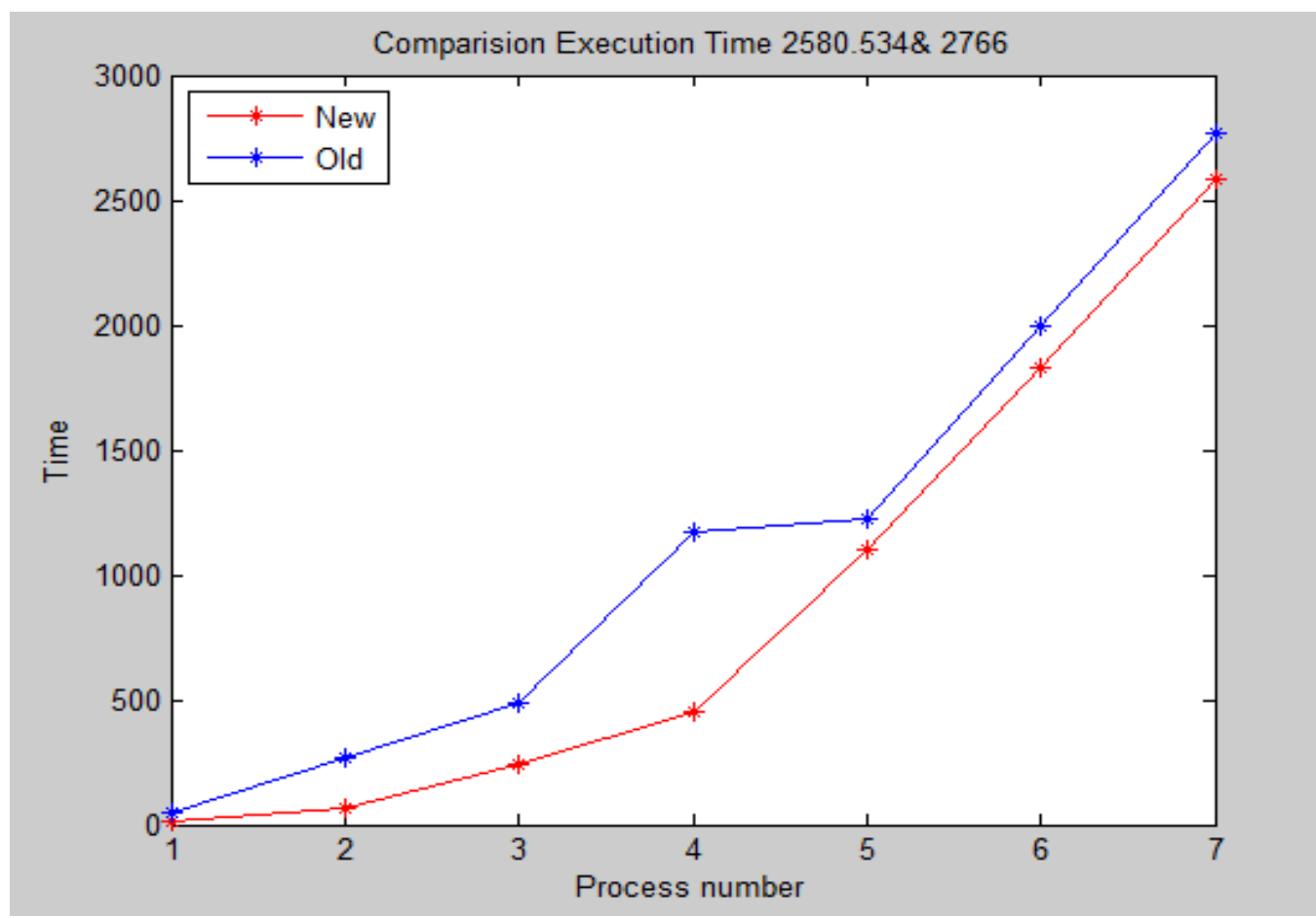

Fig: 8.9 Comparison of execution time of Greedy Latency and proposed Algorithm 


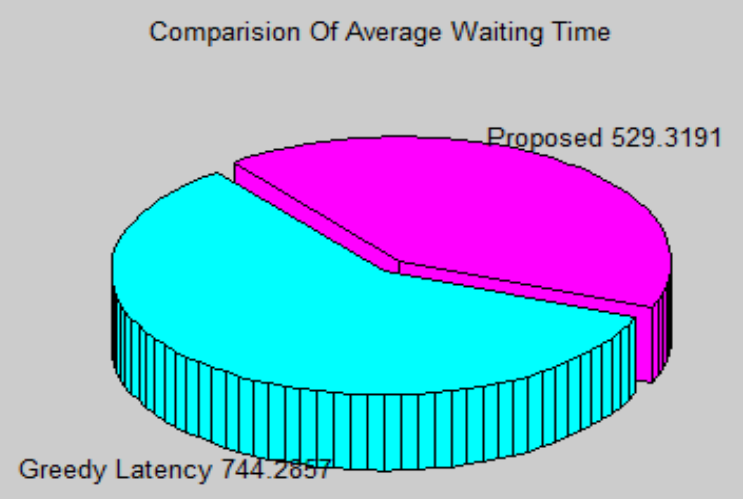

Fig: 8.10 Comparison of Average waiting time of Greedy Latency and proposed Algorithm

Fig: 8.11 Comparison of Average turnaround time of Greedy Latency and proposed Algorithm

Figure 8.10 shows the comparison of average waiting time greedy latency scheduling and proposed algorithm. The average waiting time is less in proposed scheduling

Figure 8.11 shows the comparison of average turnaround time greedy latency scheduling and proposed algorithm The comparison of average turnaround time time of proposed algorithm scheduling with greedy latency for each user shown by the pie chart in GUI Interface with yellow color on the graph. The average turnaround time is less in proposed scheduling. 
Table 7.3 Simulation Results for Greedy Latency

\begin{tabular}{|l|l|l|l|l|l|l|l|l|}
\hline $\begin{array}{l}\text { User } \\
\text { number }\end{array}$ & $\begin{array}{l}\text { Serial order of } \\
\text { process }\end{array}$ & $\begin{array}{l}\text { Name of } \\
\text { Process }\end{array}$ & $\begin{array}{l}\text { Greedy } \\
\text { Latency } \\
\text { Utility } \\
\text { Value }\end{array}$ & $\begin{array}{l}\text { Waiting } \\
\text { Time }\end{array}$ & $\begin{array}{l}\text { Packet } \\
\text { Arrival } \\
\text { Time }\end{array}$ & $\begin{array}{l}\text { Packet } \\
\text { Latency }\end{array}$ & $\begin{array}{l}\text { Maximum } \\
\text { admissible } \\
\text { Latency }\end{array}$ & $\begin{array}{l}\text { Burst } \\
\text { Time }\end{array}$ \\
\hline 5 & 1 & Web browsing & 0.375 & 0 & 34 & 60 & 160 & 51 \\
\hline 6 & 2 & $\begin{array}{l}\text { Video } \\
\text { Streaming }\end{array}$ & 0.2025 & 51 & 22 & 79 & 400 & 220 \\
\hline 2 & 2 & $\begin{array}{l}\text { Video } \\
\text { Streaming }\end{array}$ & 0.1275 & 271 & 57 & 51 & 400 & 220 \\
\hline 4 & 4 & $\begin{array}{l}\text { Media } \\
\text { download }\end{array}$ & 0.076 & 491 & 2 & 76 & 1000 & 684 \\
\hline 1 & 1 & Web browsing & 0.0313 & 1175 & 13 & 5 & 160 & 51 \\
\hline 7 & 3 & Gaming & 0.026 & 1226 & 84 & 26 & 1000 & 770 \\
\hline 3 & 3 & Gaming & 0.012 & 1996 & 42 & 12 & 1000 & 770 \\
\hline
\end{tabular}

Table 7.4 Simulation Results for Proposed Algorithm

\begin{tabular}{|l|l|l|l|l|l|l|l|l|l|}
\hline $\begin{array}{l}\text { User } \\
\text { number }\end{array}$ & $\begin{array}{l}\text { Serial } \\
\text { order } \\
\text { of } \\
\text { process }\end{array}$ & $\begin{array}{l}\text { Name } \\
\text { Process }\end{array}$ & $\begin{array}{l}\text { Greedy } \\
\text { Latency } \\
\text { Utility } \\
\text { Value }\end{array}$ & $\begin{array}{l}\text { Waiting } \\
\text { Time }\end{array}$ & $\begin{array}{l}\text { Packet } \\
\text { Arrival } \\
\text { Time }\end{array}$ & $\begin{array}{l}\text { Packet } \\
\text { Latency }\end{array}$ & $\begin{array}{l}\text { Maximum } \\
\text { admissible } \\
\text { Latency }\end{array}$ & $\begin{array}{l}\text { Burst } \\
\text { Time }\end{array}$ & $\begin{array}{l}\text { Distance } \\
\text { from Base } \\
\text { station }\end{array}$ \\
\hline 5 & 1 & $\begin{array}{l}\text { Web } \\
\text { browsing }\end{array}$ & 0.0264 & 0 & 0.5785 & 93.4215 & 160 & 17.5785 & 33.4215 \\
\hline 1 & 1 & $\begin{array}{l}\text { Web } \\
\text { browsing }\end{array}$ & 0.5839 & 17.5785 & 3.7805 & 4.2195 & 160 & 41.7805 & 9.2195 \\
\hline 6 & 2 & $\begin{array}{l}\text { Video } \\
\text { Streaming }\end{array}$ & 0.0917 & 59.359 & -18.03 & 121.025 & 400 & 179.975 & 40.025 \\
\hline 2 & 2 & $\begin{array}{l}\text { Video } \\
\text { Streaming }\end{array}$ & 0.3026 & 239.334 & 42.682 & 36.6822 & 400 & 205.6822 & 14.3178 \\
\hline 4 & 4 & $\begin{array}{l}\text { Media } \\
\text { download }\end{array}$ & 0.1024 & 445.016 & -24.42 & 102.4197 & 1000 & 657.5803 & 26.4197 \\
\hline 7 & 3 & Gaming & 0.0697 & 1102.6 & 40.319 & 69.6807 & 1000 & 726.3193 & 43.6807 \\
\hline 3 & 3 & Gaming & 0.0341 & 1828.92 & 19.909 & 34.0907 & 1000 & 747.9093 & 22.0907 \\
\hline
\end{tabular}

Table 7.5 Simulation Results for Greedy Latency and Proposed Algorithm

\begin{tabular}{|l|l|l|l|l|}
\hline S.NO & Algorithm & Average Turnaround Time & Average Waiting Time & Total Execution Time \\
\hline 1 & Greedy Latency & 1139.4286 & 744.2857 & 2766 \\
\hline 2 & Proposed & 894.8177 & 526.7698 & 2576.3353 \\
\hline
\end{tabular}

\section{CONCLUSION AND SCOPE}

The scheduling, in general help to manage so many tasks so that time can be managed to get maximum output in real life. Similarly if we consider the WiMAX the scheduling can play an important role to achieve high QoS. As the demand of high speed wireless broadband internet can increased day by day, the no of user for using the internet can also be increased day by day. To achieve these two goals the scheduling plays an important role. The scheduling algorithm will help to schedule the packet delivery for each user and hence the speed of execution can also be increased. The scheduling algorithm said to be efficient if turnaround time, waiting time, packet drop can be minimized. We design the new approach for scheduling and also we can compare all parameters of proposed algorithm with greedy latency algorithm. In our approach the execution time for all the processes are less as compare to the greedy latency algorithm. Results from our simulations using MATLAB shows that the proposed system provides a efficient scheduling algorithm. The results shows that the average turnaround time, waiting time and the burst time for each process can be reduced. This will help to increase the speed of packet delivery from base station to subscriber station. This scheduling can increase the execution of those users which are closer to the base station.

Future work can add more parameters like throughput of the network. It can also be impalement to the user which is residing more closely to the base station. As the demand of high speed broadband internet increased day by day so this approach will help increase the speed of execution for high traffic environment. This approach can be applied where the base station are closer to the users. 


\section{REFERENCES}

[1]. Andrews M., Kumaran K., Ramanan K., Stolyar A., and Whiting P., Feb 2001 "Providing Quality of Service over a Shared Wireless Link" IEEE Communications Magazine, Vol.01, pp.150-154.

[2]. Agarwal M. and Puri A. 2002 "Base station scheduling of requests with fixed deadlines" IEEE INFOCOM, Vol .02 pp. 488-496.

[3]. Anas F. Bayan and Wan T. 2010 "A Scalable QOS Scheduling Architecture for WiMAX Multi- Hop Relay Networks" 2nd International Conference on Education Technology and Computer (ICETC) pp 326-331.

[4]. Ali1 D. M., and K. Dimyati 2011 "Performance Analysis of Delay Jitter in Mobile WiMAX Systems 2011 International Conference on Information and Electronics Engineering Vol.6, Singapore pp 1 -5.

[5]. Ali D. and Dimyati K. July 2011 "Threshold based Cyclic Polling (TbCP): An Uplink Scheduling Algorithm for Mobile WiMAX Systems" International Journal of Information and Electronics Engineering, Vol. 1, No. 1, pp $1-8$.

[6]. Al-Howaide A.,Doulat A,Yaser M. and Khamayseh October 2011 "performance evaluation of different scheduling algorithms in wimax" International Journal of Computer Science, Engineering and Applications (IJCSEA) Vol.1, No.5, pp81-94.

[7]. Ahmed M. Shabani H. Beg M. and Khader A. April 2012 "Survey of DownLink Data Allocation Algorithms in IEEE 802.16 WiMAX” IRACST - International Journal of Computer Networks and Wireless Communications (IJCNWC), ISSN: 2250-3501 Vol.2, No.2, pp 293-299.

[8]. Alizadeh M. ,Dziyauddin R.*, Kaleshi D. and Doufexi A. 2012 "A comparative study of mixed traffic scenarios for different scheduling algorithms in WiMAX" IEEE 978-14673-0990 pp 1-6.

[9]. Awan K.,Abdullah A. and Qureshi K. 2013 "Resource Allocation in IEEE 802.16e Mobile WiMAX Networks: Survey" World Applied Sciences Journal 28 ISSN 18184952 IDOSI Publications, pp103-113.

[10] Anouari T. and Haqiq A. March 2014 "A QoE-Based Scheduling Algorithm for UGS Service Class in WiMAX" Network International Journal of Soft Computing and Engineering (IJSCE) ISSN: 2231-2307, Volume-4, Issue-1, pp195-199.

[11]. BINI E. and BUTTAZZO G. 2005 "Measuring the Performance of Schedulability Tests" Springer Science, Vol .30 pp. $129-153$.

[12]. Chandur P., Karthik R. and Sivalingam K. 2012 "Performance Evaluation of Scheduling Algorithms for Mobile WiMAX Networks" IEEE 978-1-4673-0906-6 pp 770-775.

[13]. Chen J.,W. Jiao and H. Wang, 2005 "A service flow management strategy for IEEE 802.16 broadband wireless access systems in tdd mode in Communications" ICC IEEE International Conference, vol. 5, pp. 3422-3426.

[14]. Dahmouni H., El Ghazi H., Bonacci D., Sansò B. and Girard A. MAY 2010 "Imprvoing QoS of all-IP Generation of Pre-WiMax Networks Using Delay-Jitter Model" Journal of telecommunications, VOL. 2, pp 99-103
[15]. Deepak H., and Nayak S. 2012,"Bandwidth Recycling in WiMAX Networks" (IJCSIT) International Journal of Computer Science and Information Technologies, Vol. 3,3852-3855.ISSN:0975-9646, pp.3852-3855.

[16]. Dosciatti R., Godoy W., and Foronda A., 2012 “An efficient approach of scheduling with call admission control to fixed wimax networks," Latin America Transactions, IEEE (Revista IEEE America Latina), vol. 10, no. 1, pp. 1256-1264,.

[17]. Gidlund M. and Wang G MARCH 2009 "Uplink Scheduling Algorithms for QoS Support in Broadband Wireless Access Networks" JOURNAL OF COMMUNICATIONS, VOL. 4,pp 133-142.

[18]. Galshetwar G., Jayakumar A. and Mittal Y. Apr 2012 "Comparative Study Of Different Scheduling Algorithms For Wimax MAC Scheduler Design" International Journal of Engineering Research and Applications (IJERA) ISSN: 2248-9622 Vol. 2, Issue 2, pp.1031-1037.

[19]. Gupta S. 2013 "Comparison of Various Scheduling Algorithms in WiMAX: A Brief Review" Published in International Journal of Computer Applications (IJCA), pp 34-36.

[20]. Haghani E. and Ansari N. 2008 "VoIP Traffic Scheduling in WiMAX Networks", IEEE 978-1-4244-2324 pp 1-8.

[21]. Kaur H. and Singh G. September 2011 "Implementation and Evaluation of Scheduling Algorithmsin Point-to-Multipoint Mode in Wimax Networks" IJCST Vol. 2, Issue 3, I S S N : 2229 - 4333 pp 540-546.

[22]. Kishor L. and Goyal D. April 2013 "Time Quantum Based Improved Scheduling Algorithm"International Journal of Advanced Research in Computer Science and Software Engineering Volume 3, Issue 4, ISSN: 2277 128X [23]. Khatkar A. 2013 "Performance Analysis of UGS and BE QoS classes in WiMAX" Advance in Electronic and Electric Engineering. ISSN 2231-1297, Volume 3, Number 7, pp. 805-810. 